\title{
POLÍTICAS DE ESTADO VERSUS POLITTICAS DE GOVERNO
}

\author{
STATE POLICIES Vs. GOVERNMENT POLICIES
}

\author{
POLÍTICAS ESTATALES Vs. POLÍTICAS \\ GUBERNAMENTALES
}

\author{
Marcelo Lima' \\ Samanta Lopes Macier \\ Michele Pazolini ${ }^{3}$
}

\begin{abstract}
Resumo: Neste trabalho, buscou-se distinguir e classificar importantes ações do governo federal com base nos conceitos de "Políticas de Estado" e de "Políticas de Governo" no período de 2011 a 2014. Contrapondo duas medidas educacionais (Expansão da Rede Federal de Educação Profissional e o PRONATEC) dos governos petistas, observamos como cada política atuou fortalecendo e ou esvaziando os direitos sociais à educação e ao trabalho. No desenvolvimento dessas políticas evidencia-se um importante deslocamento de ênfase quanto aos objetivos e resultados. No governo Lula enfatizou-se a oferta escolar para reprodução estatal ampliada para o trabalho complexo, possibilitando integração entre escolarização e profissionalização. E no governo Dilma passou-se a buscar oferta semi-escolar para reprodução privada do trabalho simples, ensejando dissociação curricular e fragmentação formativa. Movimento esse que se traduz na subsunção de uma política a outra, subordinando a formação para o mercado ao mercado da formação.
\end{abstract}

Palavras-chave: Políticas de Estado - Políticas de Governo - Direito à Educação.

\footnotetext{
${ }^{1}$ Doutor em Educação pela Universidade Federal Fluminense (UFF), com pós-doutorado em historiografia da educação profissional pela mesma universidade. Atua como docente do Departamento de Educação, Política e Sociedade do Centro de Educação da Universidade Federal do Espírito Santo (DEPS/CE/UFES), integra o quadro docente do Programa de Pós-Graduação em Educação da UFES; integra o Núcleo de Estudos, Documentação e Dados sobre Trabalho e Educação (NEDDATE/UFF), o Grupo de Pesquisa Projetos Integrados de Pesquisas sobre Trabalho, História, Educação e Saúde (THESE/UFF), o Grupo de Pesquisa Gestão, Trabalho e Avaliação Educacional e o Grupo de Pesquisa "EM pesquisa". E-mail: marcelo.lima@ufes.br

2 Mestra em Educação pela Universidade Federal do Espírito Santo. Atua como pedagoga no Campus São Mateus do Instituto Federal de Educação, Ciência e Tecnologia do Espírito Santo (IFES/São Mateus). E-mail: samanta.ifes@gmail.com

${ }^{3}$ Mestra em Educação pela Universidade Federal do Espírito Santo. Atua como Pedagoga na Prefeitura de Vila Velha/ES.
} 


\begin{abstract}
In this work, we sought to distinguish and classify important actions of the federal government based on the concepts of "State Policies" and "Government Policies" in the period from 2011 to 2014. Comparing two educational measures (Expansion of the Federal Network of Professional Education and the PRONATEC) of the PT governments, we observed how each policy acted by bringing about and depleting social rights to education and work. In the development of these policies there is an important shift of emphasis on objectives and results. In the Lula government the school supply for state reproduction amplified for the complex work was emphasized, allowing integration between schooling and professionalization. And in the Dilma government, a semi-school offer was made for private reproduction for simple work, resulting in curricular dissociation and formative fragmentation. This movement is translated into the subsumption of one policy to another, subordinating training to the market to the training market.
\end{abstract}

Keywords: State policies - Government Policies - Right to education.

Resumen: En este documento, buscamos distinguir y clasificar acciones importantes del gobierno federal con base en los conceptos de "Políticas estatales" y "Políticas gubernamentales" de 2011 a 2014. Contrastando dos medidas educativas (Expansión de la Red Federal de Educación profesional y PRONATEC) de los gobiernos petistas, observamos cómo cada política actuó al fortalecer y / o agotar los derechos sociales a la educación y al trabajo. En el desarrollo de estas políticas, hay un cambio importante en el énfasis en los objetivos y resultados. En la administración de Lula, se enfatizó la oferta escolar para una reproducción estatal ampliada para trabajos complejos, lo que permite la integración entre la escolarización y la profesionalización. Y en el gobierno de Dilma, comenzó a buscar una oferta "semi-escolar" para la reproducción privada de trabajos simples, lo que resultó en una disociación curricular y una fragmentación formativa. Este movimiento se traduce en la subsunción de una política a otra, subordinando la capacitación para el mercado al mercado de capacitación.

Palabras clave: Políticas estatales - Políticas gubernamentales - Derecho a la educación.

\title{
Introdução
}

Para conceituar políticas públicas de educação, situamo-nos na interface dos campos da pesquisa em "Trabalho e Educação" (com forte ênfase da base marxista crítica ao processo capitalista de produção e acumulação, com vista aos fundamentos ontológicos de formação humana) e em "Políticas Educacionais" (com abordagem epistemológico plural que trata criticamente a relação entre Sociedade, Estado e Educação). A produção acadêmica do campo Trabalho-Educação tem como objeto privilegiado os processos de formação e escolarização que se situam na contradição entre a reprodução da força de trabalho e formação humana integral. A produção acadêmica sobre a política educacional caracteriza-se por estudos sobre a situação de ensino no país, a administração da educação, a administração escolar e a educação comparada, mas vincula-se a interesses que estão em jogo, seja para legitimar determinada política, seja para negá-la, de modo que as tomadas de posições dos intelectuais nesse campo tanto podem contribuir com mecanismos de reprodução social como de sua transformação.

Diferenciando a ação governamental-estatal em termos anglo-saxões, Stremel (2016) afirma que a política como estrutura ou sistema político e social define-se como Polity. Esta situa-se nas relações de poder e nos jogos de forças internas à luta de classes e às frações de classe que disputam o controle do Estado. A política produzida por 
processos de interação social denomina-se como Policy. E o debate sobre alcance, consistência, racionalidade, intencionalidades e efetividade (verificável pelos beneficiários finais ou intermediários) no curto, médio e longo prazo relaciona-se ao termo Politics.

O termo Politics engloba análises que vão das ações governamentais estruturantes de Estado (que incidem e modificam infraestrutura e aplicação de longo prazo que atingem às atividades fins e beneficiam o público-alvo com efetividade social), tipo $A$, às ações governamentais efêmeras de Governo (que resultam mais em transferência de recursos que se perdem no processo beneficiando as atividades-meio, financiando estruturas burocráticas e ou privadas e alimentando interesses de operadores intermediários de serviços prestados), tipo B.

Historicamente, no campo da educação, encontramos diversas ações governamentais que podem ser classificadas por essa conceituação, dentre as quais destacamos: Programa Intensivo de Preparação de Mão-de-Obra Industrial (PIPMOI), Programa Intensivo de Preparação de Mão-de-Obra (PIPMO), Programa de Expansão e Melhoria do Ensino Médio (PREMEM), Programa de Melhoria e Expansão do Ensino Médio (PROMED), Programa de Expansão da Educação Profissional (PROEP), Plano Nacional de Formação Profissional (PLANFOR), Plano Nacional de Qualificação (PNQ) Programa Nacional de Inclusão de Jovens (ProJovem), Programa Nacional de Integração da Educação Profissional com a Educação Básica na Modalidade de Educação de Jovens e Adultos (Proeja), Programa Ensino Médio Inovador (PROEMI) e Programa Nacional de Acesso ao Ensino Técnico e Emprego (PRONATEC). Quase todas classificadas como medidas educacionais de reprodução da força de trabalho (tipo B).

Geralmente, essas políticas de iniciativa da União atendem a demandas da "sociedade" por meio de repasse de recursos públicos a instituições não estatais e/ou de uma ação direta das redes públicas (federal, estadual e ou municipal). Tais ações possuem impacto nas políticas públicas de educação, criando um campo de disputa pela hegemonia no estabelecimento das prioridades educacionais nos planos financeiro, econômico, ideológico e pedagógico.

No campo educacional, esses programas podem deixar como legado obras realizadas, formação de professores, laboratórios e equipamentos instalados na estrutura escolar, resultando em benefícios de longo e/ou de médio prazo. No entanto, quando as ações se resumem ao repasse de recursos públicos ao setor privado, os resultados podem reduzir-se à capitalização e ao fortalecimento de instituições e/ou de seus proprietários e dirigentes. Diante disso, as consequências podem ser a sobreposição dos meios, contratação de entidades privadas para prestação de serviços públicos, aos fins, atendimento ao público-alvo. Nesse último caso a transparência e a fiscalização dos repasses e resultados tornam-se fundamentais para se avaliar a qualidade efetiva da medida educacional.

Além do mais, tais ações praticadas rompem um pressuposto fundamental: o de que o fundo público deve financiar o direito à educação que se estrutura por meio de políticas públicas permanentes, atendendo a todos os indivíduos universalmente e de forma obrigatória em ação direta e/ou colaborativa entre os entes públicos federados. Ou seja, num sistema nacional de educação, o setor privado teria função complementar e não substitutiva, posto que, a educação é um direito, o que requer manter sua oferta 
estruturalmente pública. Do contrário, submetidas, sua gestão e/ou execução, à esfera privada, a educação tende a ter distorcidos seus objetivos mais fundantes, relacionados com a promoção da emancipação humana e do bem comum.

Do ponto de vista sistêmico, uma política precisa ser avaliada em relação a outras. No conjunto das políticas sociais, muitas ações são convergentes e complementares, mas há casos de justaposição e/ou de concorrência entre as iniciativas estatais e/ou privadas financiadas pelo fundo público. $O$ discurso neoliberal e gerencialista hegemônico tem valorizado determinadas ações em detrimento de outras. Ações de gestão e/ou de execução estatal com efeito de longo prazo, de alcance universal, democraticamente geridas e de custos maiores podem subordinar-se politicamente às ações de gestão e/ou de execução privada com resultados de curto prazo, de alcance seletivo e de custos menores.

No que se refere as políticas públicas de qualificação profissional, articuladas ou não com processos de escolarização, estas são colocadas em prática com o argumento da falta de mão de obra qualificada e inspiram-se nos princípios da teoria do capital humano, em decorrência do crescimento econômico ou com objetivo de impulsioná-lo. Exemplo disso está no Projeto de Lei que institui o PRONATEC, altera as Leis $n^{\circ} 7.998 / 90$, $n^{\circ} 8.212 / 91$ e $n^{\circ} 10.260 / 2001$, com fito de [...] ampliar a oferta de educação profissional e tecnológica por meio de programas, projetos e ações de assistência técnica e financeira" (BRASIL, 2011) que, em sua exposição de motivos, encaminhada à apreciação da presidente à época, Dilma Rousseff, classifica a falta de mão de obra qualificada como um dos "[...] maiores desafios colocados hoje para continuidade do crescimento econômico do País" (BRASIL, 2011).

Muitas vezes, tais políticas desarticulam-se de processos mais amplos de escolarização, servindo menos a objetivos estruturantes da oferta pública escolar e mais a objetivos secundários de fortalecimento de setores privados de formação profissional. Retomando a premissa de que o fundo público deve financiar o direito à educação por meio de políticas públicas permanentes de atendimento a todos, universalmente e de forma obrigatória, em ação direta e/ou colaborativa dos entes públicos federados, cabe uma análise dos processos de formulação e implementação dessas políticas.

Entendendo que a garantia do direito à educação está ligada à atuação do Estado, pois, na medida em que os princípios de gratuidade e obrigatoriedade atravessam esse direito, a figura do Estado se torna indispensável a sua concretização, é mister salientar que esse direito está inserido no rol dos direitos fundamentais entendidos como "[...] direitos do homem consagrados pelo Estado nacional em suas cartas constitucionais que tem como nota distintiva sua fundamentalidade, ou seja, sua indispensabilidade para o ser humano" (SCAFF; PINTO, 2016, p. 437).

Para Cury (2014), ao ser incluído no Título II - Capítulo II da Constituição Federal de 1988 (CF88), "Dos direitos e das Garantias Fundamentais", o direito à educação caracteriza-se como elemento constituinte da cidadania. Nesse sentido, Scaff e Pinto (2016) salientam que a inserção desse direito como direito fundamental requer do Estado um comportamento essencialmente ativo para sua efetivação.

Ademais, o acesso ao ensino obrigatório e gratuito teve sua principal afirmação quando declarada aos cidadãos, na CF88, Art. 208, $\$ 1^{\circ}$, como "direito público subjetivo". 
Isso significa "[...] o poder de ação que a pessoa possui de proteger ou defender um bem considerado inalienável e ao mesmo tempo legalmente reconhecido" (HORTA, 1998 , p. 8), podendo exigir seu cumprimento da parte responsável. Duarte $(2004$, p. 113) entende como direito público subjetivo a

\begin{abstract}
[...] capacidade reconhecida ao indivíduo em decorrência de sua posição especial como membro da comunidade, que se materializa no poder de colocar em movimento normas jurídicas no interesse individual. [...] o direito público subjetivo confere ao indivíduo a possibilidade de transformar a norma geral e abstrata contida num determinado ordenamento jurídico em algo que possua como próprio. A maneira de fazê-lo é acionando as normas jurídicas (direito objetivo) e transformando-as em seu direito (direito subjetivo). [...] configura-se como um instrumento jurídico de controle da atuação do poder estatal, pois permite ao seu titular constranger judicialmente o Estado a executar o que deve.
\end{abstract}

O direito à educação pode ser definido como direito de todos os cidadãos, de acesso gratuito em todos os seus níveis e obrigatório, sendo dever da família matricular seus filhos e, do Estado, ofertar o ensino obrigatório (HORTA, 1998), que abrange a faixa etária de 4 a 17 anos na legislação atual. Scaff e Pinto (2016, p. 438) advertem que:

A afirmação do direito à educação como um direito fundamental de natureza social tem uma consequência importantíssima, visto que, por intermédio dela, reconhecese que, embora o direito à educação possa ser efetivado e exigido judicialmente de maneira individual, sua concretização ocorrerá por meio da realização de políticas públicas.

Destarte, retomamos a discussão acerca das políticas públicas voltadas à garantia do direito à educação. No caso particular dos projetos e programas tomados aqui como políticas de Governo e não de Estado, outras contradições se acentuam devido ao caráter efêmero e não estruturante do conjunto de suas ações. Consideramos, para efeito de nossa análise, que quanto mais imediatistas as premissas que orientam tais políticas, provavelmente mais distorções e inversões entre objetivos e resultados podem ocorrer. Nos últimos anos, nenhum governo atuou de modo a constituir um sistema nacional de educação, consolidando o direito à educação e produzindo a subsunção das políticas de Governo às políticas de Estado.

Esse direito possui característica prestacional, ou seja, sua concretização depende de atuação direta do Estado. Daí, infere-se que, apesar da repartição de competências, dando a cada ente federado a responsabilidade por determinada etapa, todos têm, segundo sua capacidade técnica e financeira, a incumbência comum de assegurar o direito à educação básica. Para Werle (2016), a universalização do ensino obrigatório "[...] é responsabilidade compartilhada por todas as esferas administrativas. Esta responsabilidade não é apenas uma declaração, mas precisa expressar-se em recursos e ações efetivas" (p. 185). Dourado (2016, p. 42) conclui que "[...] proporcionar os meios de acesso à educação é dever de todos os entes federados e que sua efetivação deve ser resultante da cooperação e colaboração".

Além disso, a LDB e a CF88 afirmam que o não oferecimento do ensino pelo Poder Público (ou sua oferta irregular) importa responsabilidade da autoridade competente. Portanto, há o reconhecimento dos fundamentos jurídicos do direito à educação e de sua relevância como direito social, cabendo ao Estado a obrigação de atender, na maior medida possível, às necessidades imediatas de todos os cidadãos por meio de ação 
governamental eficiente e eficaz (COSTA, 2014). Esse direito implica, reiterando, a letra da constituição, que a educação básica é competência comum dos três entes federativos, ultrapassando, portanto, os limites administrativos das redes (ABCALIL, 2016).

Apesar disso, historicamente, o Governo Federal vem transferindo obrigações com a oferta escolar da educação básica e profissional. Essa redistribuição, embora aponte na perspectiva de avanço do regime de colaboração, não sendo regulamentada, permite à esfera federal atuar com bastante autonomia por meio do que a legislação denominou de assistência técnica e/ou financeira a sua rede ou a rede de outros entes (estados, municípios e Distrito Federal). Ademais, a União vem articulando-se com o setor privado, disponibilizando recursos vultosos para materializar projetos políticos e pedagógicos, produzindo o encontro ou o desencontro da educação básica com a educação profissional (EP).

Para analisar a relação entre Políticas de Estado e Políticas de Governo, tomamos alguns elementos empíricos das ações do governo federal no período de 2011 a 2014 Metodologicamente, tomamos a gestão federal da oferta da educação básica na sua articulação (integrada ou não) com a EP, tendo como objeto a comparação das escolhas por ações diretas (Expansão dos Institutos Federais e congêneres) ou indiretas (transferência de recursos para planos nacionais de qualificação).

No governo Fernando Henrique Cardoso, num contexto de recuperação da economia, houve um processo de estagnação da estrutura física da rede federal de educação profissional combinada à dissociação curricular (Decreto $n^{\circ}$ 2208/1997), que resultou numa cefetização ${ }^{4}$ desta rede com contornos privatizantes bastante evidentes. Ademais, foi criado o PLANFOR, que promoveu a transferência de recursos para o setor privado, com participação importante do Sistema $\mathrm{S}^{5}$.

No governo Lula, num cenário de crescimento econômico e alívio fiscal, houve intenso processo de expansão da rede federal e de reintegração curricular (Decreto $\mathrm{n}^{\circ}$ 5.154/2004). Foram criados o Programa Brasil Profissionalizado (PBP) (Decreto $\mathrm{n}^{\circ}$ 6.302/2007), que repassou recursos para a estruturação das redes estaduais de escolas de ensino médio e de EP, e um novo PNQ 2003-2007 (Resolução CODEFAT n³33, de 10 de julho de 2003) que, apesar de articular-se com os municípios para a elevação da escolarização, repassou significativos recursos para o setor privado, sobretudo para o Sistema S.

No governo Dilma, temporalidade aqui em análise, houve um momento inicial de condição econômica favorável, razão pela qual se afirmava, no início do primeiro mandato, o fortalecimento do Programa de Aceleração do Crescimento (PAC) e o combate ao chamado "apagão de mão de obra", justificativa para criação do PRONATEC. Esse cenário exauriu-se logo no início do seu segundo mandato, levando o país à grave crise econômica e extremo arrocho fiscal, que afetaram a expansão da rede federal.

${ }^{4} \mathrm{O}$ termo refere-se à transformação das escolas técnicas federais em CEFETs (CAMPELLO, 2006.).

${ }^{5}$ Conjunto de entidades corporativas - Serviço Nacional de Aprendizagem Industrial (Senai); Serviço Social do Comércio (Sesc); Serviço Social da Indústria (Sesi); e Serviço Nacional de Aprendizagem do Comércio (Senac) - de treinamento profissional, assistência social, consultoria, pesquisa e assistência técnica. 
Quais seriam, pois, as implicações das escolhas do Governo Federal ao implementar medidas educacionais subsumindo os interesses majoritários da sociedade com políticas de governo?

\section{Desenvolvimento}

Na busca de verificar o processo de subsunção das políticas de Estado às políticas de Governo, passamos a analisar o direito à educação no contexto das políticas de EP do governo federal no período de 2011 a 2014.

O Estado, ao mesmo tempo em que se configura como espaço de contradição e disputa, expressando o movimento de classes, acentua, em períodos de crise, o papel histórico de agente regulador do capital, atuando no seio das contradições sociais gestadas pelo próprio capitalismo, assegurando direitos sociais ou reduzindo-os dentro do constante jogo de forças (POULANTZAS, 1980; HIRSCH, 2010).

Em uma conjuntura de constantes contradições sociais de um sistema que não abrange a todos, um conjunto de teses e teorias é produzido para justificar e diminuir pressões sociais e promover uma convivência amistosa entre as classes sociais. A Teoria do Capital Humano, criada nas décadas de 1960 e 1970 foi utilizada com esse objetivo, tornando-se consenso explicativo do crescimento dos países desenvolvidos e da mobilidade social.

Essa teoria, em seu aspecto renovado (FRIGOTTO, 2015), ainda é usada como pano de fundo para a formulação de programas educacionais que trazem a promessa de desenvolvimento social e, simultaneamente, difundem a ideia de um mito de qualificação que, combinado às competências requeridas pela sociabilidade neoliberal (GENTILLI, 1998), produzem um processo que centra no sujeito a responsabilidade por sua ascensão social, negando a divisão da sociedade em classes sociais e o fato de que o capitalismo nutre-se e mantém-se a partir da exploração de classe.

No contexto do desenvolvimento do capital, a relação entre trabalho e educação foi historicamente cindida em decorrência do próprio desenvolvimento da forma trabalho no modo de produção capitalista (SAVIANI, 2007). Assim, a divisão da sociedade em classes foi determinante para a divisão da educação em modalidades diferenciadas, formando um tipo de oferta educacional para o trabalho e uma para o prosseguimento nos estudos.

Configura-se, pois, fundamental o resgate do trabalho como princípio educativo (elemento perdido com a separação entre educação e trabalho); como base do conhecimento humano em seu sentido ontológico e, portanto, como prática de liberdade e direito de todos, capaz de formar um cidadão que domine os diversos fundamentos e técnicas usadas na produção (politécnicos) e não apenas uma parcela reduzida dela.

Entendendo que trabalho e educação possuem relação histórico-ontológica e que o resultante dessa relação é o saber socialmente produzido e coletivamente elaborado, vemos o direito à educação como aquele capaz de assegurar aos cidadãos, independentemente de suas classes sociais, o acesso a esse saber. Com a escola 
constituída, historicamente, como local de apropriação desse saber, o acesso e a universalização da escolarização constituem-se direitos a serem assegurados pelo Estado.

Destarte, consideramos o Ensino Médio Integrado (EMI) a modalidade educacional capaz de sistematizar o direito à educação e ao trabalho, constituindo-se travessia para a educação politécnica e modalidade importante na superação da dualidade entre formação para trabalho manual versus formação para o trabalho intelectual.

No que tange à análise da legislação e dos dispositivos legais relacionados, percebe-se o trabalho como um direito em muitos instrumentos legais (CF88, LDB $n^{\circ}$ 9.394/1996, Decreto 5.154/2004 e PNE 13.005/2014). No entanto, a formação que visa preparar para o trabalho, ainda que situada no rol do direito, é lançada à condição de mercadoria quando, nesses dispositivos, é tratada como aquela que deverá preparar para o emprego (Decreto $n^{\circ} 5.154 / 2004$ ) e formar o indivíduo para se adaptar com flexibilidade às novas condições de ocupação (LDB). Destarte, o sentido da EP como direito é esvaziado quando passa a ter como fim formar produzindo habilidades e competências para um mercado de trabalho cada vez mais restrito.

Outro aspecto relevante encontrado nos dispositivos legais refere-se à afirmação, ao menos como pressuposto teórico, da necessidade de superação da dualidade da oferta educacional, herdada da divisão técnica do trabalho, que a fragmentou, afetando o processo de qualificação profissional.

A superação dessa dualidade está como pressuposto da EP nos grandes marcos como a LDB n 9.394/2004, o Decreto n 5154/2004 e o Plano Nacional de Educação 2014-2024 e nos marcos específicos da expansão da RFEPCT e do PRONATEC, embora, nesse último, tenhamos percebido, no aspecto prático, que esse pressuposto teórico não se efetivou.

Com base na análise desses dispositivos, observa-se que a expansão da RFEPCT e a criação dos IFs (Lei $n^{\circ} 11.892 / 2008$ ) representaram um avanço quando dilataram o papel do Estado e a oferta pública de EP, ao ampliar o acesso a educação profissional (a partir da abertura de novas escolas federais; da diversificação na oferta de cursos na forma EMI; da interiorização, que retirou a EP pública da condição de exclusividade dos grandes centros urbanos).

Quanto ao PRONATEC, a legislação também promove algum avanço, sobretudo no que tange à ampliação da rede física e das vagas na rede federal. Todavia, a legislação retrocede ao salientar a colaboração da iniciativa privada para execução da modalidade via Bolsa-Formação', fortalecendo a formação para o mercado e um tipo de oferta que se distancia da integrada, concebida por nós como aquela que se situa como direito.

Analisando-se os indicadores nacionais das políticas de educação básica e profissional do governo federal no período, pode-se verificar o processo de materialização do dever do Estado em duas vias assumidas pela ação governamental: a expansão da rede federal e o PRONATEC, confirmados nos indicadores apresentados a seguir.

${ }^{6}$ Bolsa-Formação: modalidade de oferta prevista dentro do programa na forma cursos de qualificação profissional e/ou técnicos, dissociada elevação da escolaridade. 
Observando os dados de 2007 a 2014, na Tabela 01, nota-se que a EP de nível médio no Brasil apresentou crescimento significativo. No entanto, as matrículas que integram a EP com o ensino médio (EMI) têm participação relativa bem menor que as formas não integradas (modalidades concomitante e subsequente).

Tabela 01 - Matrículas na EPTNM por rede pública e privada (2007 a 2014)

\begin{tabular}{|c|c|c|c|c|c|c|c|}
\hline \multirow{2}{*}{ Anos } & \multicolumn{2}{|c|}{ Integrado } & \multicolumn{2}{|c|}{ Concomitante } & \multicolumn{2}{|c|}{ Subsequente } & \multirow{2}{*}{ Total } \\
\hline & Pública & Privada & Pública & Privada & Pública & Privada & \\
\hline 2007 & 71.364 & 15.188 & 161.230 & 155.768 & 160.414 & 216.198 & 780.162 \\
\hline 2008 & 115.406 & 17.113 & 203.667 & 175.493 & 160.141 & 256.158 & 927.978 \\
\hline 2009 & 154.194 & 21.637 & 186.694 & 119.341 & 196.763 & 358.316 & 1.036 .945 \\
\hline 2010 & 193.565 & 22.150 & 104.539 & 112.011 & 297.711 & 410.409 & 1.140 .385 \\
\hline 2011 & 236.130 & 21.584 & 94.679 & 93.893 & 338.953 & 465.662 & 1.250 .901 \\
\hline 2012 & 273.431 & 25.114 & 106.277 & 133.949 & 350.042 & 473.387 & 1.362 .200 \\
\hline 2013 & 312.122 & 26.268 & 109.392 & 200.584 & 328.161 & 464.524 & 1.441 .051 \\
\hline 2014 & 337.865 & 29.094 & 115.142 & 213.383 & 331.756 & 714.288 & 1.741 .528 \\
\hline
\end{tabular}

Os dados da Tabela 01 confirmam que, no que se refere à oferta de EMI, maior parte das matrículas se concentra na rede pública e que a oferta, pela rede privada, ainda é muito tímida. Na oferta pública, segundo INEPDATA (acesso 20 ago. 2016), é significativa a participação da rede estadual (127 mil alunos matriculados em 539 estabelecimentos em 2014), o que denota a necessidade de expansão da rede federal. Razão pela qual, entre 2003 e 2010 (durante os dois mandatos do governo Lula), ampliou-se o número de unidades físicas de escolas federais de 140 para 339 unidades (BRASIL, 2009) e entre 2011 e 2014, no primeiro mandato do governo Dilma, foram inauguradas 200 novas unidades na RFEPCT 7 .

Nesse caso, no fortalecimento e na expansão da rede federal, historicamente, reconhecida como de melhor qualidade na oferta da formação integrada para o trabalho complexo, tem-se uma política que pode ser classificada como ação de Estado, de longo prazo e provedora dos direitos sociais à educação e ao trabalho.

Além disso, foi instituído o PBP pelo Decreto n 6.302/2007 que no governo Lula passou a ser opção estatal à expansão da rede federal, reforçando o pacto federativo e o regime de colaboração, descentralizando a oferta pública de EMI e financiando a ampliação física das redes estaduais ofertantes dessa modalidade. Posteriormente esse

${ }^{7}$ Em 2014 o número de matrículas na rede federal no EMI alcançou 53.5\% do total de matrículas (INEPDATA, 2016). 
programa foi incluído no PRONATEC, em 2011, e vinculado ao Plano de Metas Compromisso Todos Pela Educação e ao Plano de Ações Articuladas (PAR)8.

Entretanto, embora o governo federal no período de 2011 a 2014 tenha se movimentado pela ampliação da rede federal e pelo fortalecimento das redes estaduais, por meio do PBP, a partir de um determinado momento, o governo Dilma, buscando identidade própria, estabelece uma inflexão na política para educação básica e profissional. Acreditamos que a emergência dos primeiros sinais de uma nova fase da crise do capital já se expressava pela aproximação entre os indicadores da arrecadação federal e do custeio crescente do MEC; e isso, explica a criação dessa nova política.

Assim, instituiu-se o PRONATEC, que produziu importante reconfiguração da matrícula na EP, revertendo a expansão da oferta pública, conforme apontam os dados do Relatório de Gestão do MEC (BRASIL, 2014) conforme tabela 02.

Tabela 02 - Matrículas realizadas do PRONATEC (2011 a 2014)

\begin{tabular}{|c|c|c|c|c|c|c|}
\hline \multirow{2}{*}{\multicolumn{2}{|c|}{ Cursos }} & \multicolumn{4}{|c|}{ Período } & \multirow{2}{*}{ Total } \\
\hline & & 2011 & 2012 & 2013 & 2014 & \\
\hline \multicolumn{7}{|c|}{ Cursos Técnicos } \\
\hline & Bolsa-Formação & 0 & 101.541 & 304.966 & 151.313 & 406.507 \\
\hline & Brasil Profissionalizado & 82.832 & 79.770 & 70.355 & 233.781 & 232.948 \\
\hline & E-TEC & 75.364 & 134.341 & 137.012 & 250.000 & 346.717 \\
\hline & Acordo Sistema S & 85.357 & 102.807 & 132.289 & 161.389 & 320.453 \\
\hline & Rede Federal de EРCT & 117.621 & 119.274 & 121.958 & 101.160 & 358.853 \\
\hline \multicolumn{7}{|c|}{ Cursos FIC } \\
\hline & Bolsa-Formação & 22.876 & 531.101 & 1.243 .047 & 1.013 .027 & 1.797 .024 \\
\hline & Acordo Sistema S & 582.931 & 733.223 & 844.581 & 1.194 .266 & 2.160 .735 \\
\hline Total & & 966.972 & 1.802 .057 & 2.854 .208 & 3.104 .936 & 5.922 .869 \\
\hline
\end{tabular}

Fonte: Elaborada pelos autores com base em Ministério da Educação (Brasil, 2013, p. 21).

Os dados acima demonstram que a modalidade da EP que mais cresceu após criação do PRONATEC foi a Formação Inicial e Continuada (FIC) que, em 2013, teve mais de 2 milhões de matrículas, das quais 1,2 milhões via Bolsa-Formação Trabalhador. Já os cursos técnicos, no mesmo ano, totalizaram cerca de 750 mil matrículas, sendo mais de 300 mil no Bolsa-Formação Estudante (BRASIL, 2014, p. 21). Assim, a Bolsa Formação representou a ação financiada pela união de maior expressão do PRONATEC desde 2011.

${ }^{8}$ Os recursos financeiros repassados para os estados pelo PBP, segundo o Ministério da Educação (MEC), destinam-se à construção, reforma e modernização de escolas técnicas, contando com a estruturação de laboratórios, recursos pedagógicos, formação e qualificação dos profissionais atuantes na educação. Desde sua implementação, em 2007, até o ano de 2016, o programa atendeu instituições de 24 estados brasileiros. Os resultados apresentados pelo MEC apontam para 342 obras concluídas, dentre as quais, 86 novas escolas, 256 ampliações e reformas e 635 laboratórios para aulas práticas (BRASIL, 2013, p. 21). 
O Relatório de Gestão do MEC (exercício 2014) destaca o PRONATEC como o esforço mais relevante já realizado pelo Governo Federal em relação a EP. Para o governo federal, "O PRONATEC constitui o esforço mais representativo para elevar o número de matrículas em cursos de educação profissional e tecnológica". Neste programa, "foram realizadas, entre 2011 e 2014, mais de 8,1 milhões de matrículas em cursos técnicos e cursos FIC" que objetivam formar e qualificar os beneficiários para o trabalho simples (BRASIL, 2015, p. 94).

Observando um pouco a frente ao período estudado, percebemos que quanto aos tipos de cursos ofertados, só no primeiro semestre de 2015 o total de matrículas em cursos FIC já havia alcançado mais de 818 mil. Paralelamente, as matrículas em cursos técnicos no Bolsa-Formação registravam a metade do número de matriculados em cursos FIC para o período de 2015/01, indicando prioridade do Governo Federal em relação à EP para cursos de curta duração e baixa qualificação.

No que se refere à Educação de Jovens e Adultos (EJA), embora o PRONATEC tenha incorporado a elevação da escolaridade, a oferta na forma integrada para esse segmento no ano de 2013 foi insignificante, como pode-se ler no próprio relatório de gestão do MEC 2014.

De acordo com os dados do Censo Escolar 2013, no Brasil foram realizadas mais de 3,7 milhões matrículas iniciais na educação de jovens e adultos (EJA). Considerando as matrículas de EJA na forma articulada à educação profissional e as 43.406 matrículas no ProJovem no mesmo ano, alcançamos o índice de $3 \%$ de matrículas de EJA integrada à educação profissional (BRASIL, 2015, p. 96).

Alarmante foi a participação dos ofertantes de EP no âmbito do PRONATEC. Os dados apontam que o Sistema $S$ foi responsável por $85,7 \%$ das matrículas em cursos FIC (2011 a 2015), enquanto os IFs matricularam o inexpressivo percentual de $11,4 \%$ e as redes estaduais e municipais, $2,6 \%$. Somente o Senai matriculou, no período, $46,4 \%$ dos estudantes.

Ao que se refere à oferta de cursos técnicos, os dados evidenciaram maior participação entre as redes públicas, das quais os IFs registraram $34,6 \%$ e as redes estaduais e municipais, $21 \%$, embora a participação do Sistema $S$ e de instituições privadas tenha permanecido alta.

Em relação aos recursos repassados especificamente para as duas ações aqui em discussão, expansão da RFEPCT e Bolsa-Formação, observamos uma disparidade intrigante na destinação de recursos. Os investimentos na expansão da RFEPCT, desde 2011, segundo Relatório de Gestão do MEC 2014, foram da ordem de 3,3 bilhões, sendo 678 milhões só no ano 2014.

\footnotetext{
Os investimentos no Plano de Expansão e Reestruturação da Rede Federal desde 2011 foram de $R \$ 3,3$ bilhões, sendo $R \$ 678$ milhões em 2014. [...] A Rede Federal de educação profissional, Científica e Tecnológica cobre todos os estados brasileiros, oferecendo cursos técnicos, superiores de tecnologia, licenciaturas, mestrado e doutorado [...] (BRASIL, 2015, p. 93)
}

Em relação ao Bolsa-Formação, o Relatório de Gestão 2013 informa que "[...] Em 2013, o investimento no PRONATEC/Bolsa-Formação foi da ordem de R\$2,7 bilhões" (BRASIL, 2014, p. 25). Já no ano de 2014 "[...] os investimentos da iniciativa somam $R \$$ 
3,8 bilhões" (BRASIL, 2015, p. 93). Ou seja, os investimentos na Bolsa-Formação, até 2014, corresponderam a cerca de 950 milhões por ano, superior ao praticado na Rede Federal no ano de 2014, que foi de 678 milhões.

Frente à análise, desvela-se a contradição nos investimentos educacionais durante o governo Dilma com a criação do PRONATEC enquanto política de expansão da EP. Ao priorizar o financiamento de cursos de baixa qualificação ofertados em instituições privadas e no Sistema $\mathrm{S}$ (hoje ligados aos interesses da classe econômica mais poderosa do país) em detrimento da oferta de cursos de maior tempo de duração, aponta para um esvaziamento do papel do Estado diante da garantia da EP como direito. Em paralelo, vê-se o fortalecimento das redes públicas de ensino através da destinação de recursos para oferta de cursos e a construção de número significativos de novas unidades dentro da Rede Federal o que depõe para o fortalecimento da oferta pública em consonância com os pressupostos aqui explicitados.

\section{Conclusão}

A pesquisa evidenciou que a expansão da RFEPCT tem fortalecido a EP pública e de qualidade ao produzir um deslocamento da oferta federal gratuita dos grandes centros urbanos para o interior, possibilitando a ampliação do acesso e fortalecendo o direito à educação à medida em que torna menos seletiva a matrícula escolar em escolas de infraestrutura que contam com maior aporte de financiamento a suportar recursos humanos e materiais de qualidade superior ao usual na oferta pública. Isso nos permite concluir que a política de expansão da RFEPCT, iniciada no governo Lula, pode ser considerada uma ação estatal estruturante que tende ao fortalecer a oferta de uma escolarização e profissionalização na perspectiva do direito.

Já o PRONATEC, embora tenha incorporado em seu rol de ações a ampliação e o fortalecimento da RFEPCT, prevendo a ampliação física e de vagas e que, ainda que o governo Dilma tenha criado sobre a vigência do PRONATEC mais IFs em 4 anos do que Lula em 8, ao priorizar a qualificação profissional na oferta de cursos FIC e atuar na conciliação entre a oferta pública e a oferta "privada", impacta o direito à EP em dois níveis: aligeirando e desfavorecendo o conceito de qualificação; tornando a EP mais comercializável na medida em que, ao ofertar cursos de carga horária deduzidas, em um curto espaço de tempo, uma maior quantidade de cursos pode ser realizada por uma mesma instituição, comprovado pelo quantitativo de cursos executados pelo Sistema S e pelo setor privado da educação via Bolsa-Formação.

Esse movimento demonstra que o Estado promove concessões impostas pelas classes populares (no caso da educação pública, via RFEPCT), ao mesmo tempo concedendo benefícios às elites econômicas (transferindo recursos para execução de cursos no PRONATEC) apontando para uma contradição no governo Dilma, quanto ao papel do Estado como garantidor do direito à educação, ao verificar-se que a prioridade de investimentos incidiu, de forma massiva, com o PRONATEC, sobre o financiamento de cursos de baixa qualificação, ofertados em instituições privadas e no Sistema $S$, em detrimento da oferta de cursos de maior tempo de duração e do fortalecimento da oferta pública, gratuita e de qualidade nas redes públicas de ensino. 
No que se refere a RFEPCT, observamos que, após a edição do PRONATEC em 2011, outras políticas garantidoras do direito a educação passaram a ser suprimidas, particularmente o Proeja'. Assim, se anteriormente a elevação da escolaridade articulada à EP era prioridade do governo Lula, no governo Dilma assistimos à retração da oferta de EJA integrada à EP e o avanço da oferta de cursos de curta duração e baixa qualificação, como evidenciaram os dados da RFEPCT.

O PRONATEC, como política pública de educação profissional, pode ser considerado uma política de governo, sem garantias de perenidade e continuidade, que pode ser desativada a qualquer momento, de acordo com interesses políticos e com a troca de governo. Ademais, por não assegurar como ação central a elevação da escolaridade na forma integrada, o programa não é capaz de garantir o direito à educação. Deste programa, sobreviverá apenas a ação "Ampliação dos institutos" já que esse estão protegidos por Lei própria, no entanto sem garantias de investimentos, ampliação de recursos ou abertura de novas unidades.

Assim, reiteramos que a efetivação do direito a educação, no caso deste texto, da educação profissional, carece de ações sistêmicas e perenes por parte do Estado, de forma que sua oferta não fique refém das mudanças de governo e que sejam garantidas condições de acesso, permanência, sucesso, qualidade, gratuidade e universalidade para todos os cidadãos, o que passa pelo fortalecimento da escola pública, garantia de investimentos para manutenção e ampliação de estruturas físicas e valorização dos profissionais da educação.

Neste trabalho, buscou-se distinguir e classificar importantes ações do governo federal com base nos conceitos de "Políticas de Estado" e de "Políticas de Governo" no período de 2011 a 2014. Contrapondo duas medidas educacionais (Expansão da Rede Federal de Educação Profissional e o PRONATEC) dos governos petistas, observamos como cada política atuou fortalecendo e ou esvaziando os direitos sociais à educação e ao trabalho. No desenvolvimento dessas políticas evidencia-se um importante deslocamento de ênfase quanto aos objetivos e resultados. No governo Lula enfatizouse a oferta escolar para reprodução estatal ampliada para o trabalho complexo, possibilitando integração entre escolarização e profissionalização. E no governo Dilma passou-se a buscar oferta semi-escolar para reprodução privada tendo em vista o trabalho simples, ensejando dissociação curricular e fragmentação formativa. Movimento esse que se traduz na subsunção de uma política a outra, subordinando a formação para o mercado ao mercado da formação.

Hoje, depois do golpe contra a presidenta Dilma em 2016 e com a reforma do ensino médio em curso, e com as matrículas do PRONATEC chegando a cerca de 10 milhões com gastos totais da monta de 15 bilhões, com forte ênfase em curso FIC de oferta privada (sobretudo Sistema S), perguntamos qual o legado dessa política para o direito à educação?

Certamente, os dados aqui apresentados não nos permitem aferir definitivamente os efeitos de um programa tão amplo e abrangente na inserção dos egressos, no

\footnotetext{
9 Programa Nacional de Integração da Educação Profissional com a Educação Básica, na modalidade de Educação de Jovens e Adultos criado durante o governo Lula pelo Decreto 5840/2006 que assegura obrigatoriedade de oferta de 10\% das vagas dos Institutos Federais na modalidade EJA.
} 
desenvolvimento econômico, na inclusão e na mobilidade social, mas podemos afirmar que essa política primou pela formação para o mercado pela via do mercado da formação, fazendo subsumir a política de Estado à políticas de Governo, exaurindo uma possível função mediadora para sobrepor uma função imediatista, mercantilista e economicista da educação.

\section{Referências}

ABCALIL, C. A. O Sistema Nacional de Educação, Relações Federativas e Cooperação. In: DOURADO, L. F., AZEVEDO, J. M. L. Relações Federativas e Sistema Nacional de Educação (Orgs.). Camaragibe. PE. CCS Gráfica e Editora, 2016.

BRASIL. Constituição (1988). Constituição da República Federativa do Brasil. Brasília, DF: Senado Federal: Centro Gráfico, 1988. 292 p.

Lei 9.394, de 20 de dezembro de 1996. Estabelece as diretrizes e bases da educação nacional. Diário Oficial da União - Seção 1 - 23/12/1996, Página 27833. Brasília, 1996.

Decreto 2.208, de 17 de abril de 1997. Regulamenta o $\S 2^{\circ}$ do art. 36 e os arts. 39 a 42 da Lei no 9.394, de 20 de dezembro de 1996. Diário Oficial da União - Seção 1 - 18/4/1997, Página 7760. Brasília, 1997.

Decreto 5.154, de 23 de junho de 2004. Regulamenta o $\S 2^{\circ}$ do art. 36 e os arts. 39 a 41 da Lei no 9.394, de 20 de dezembro de 1996. Diário Oficial da União - Seção 1 - 26/7/2004, Página 18. Brasília, 2004.

MTE. Plano Nacional de Qualificação do Trabalhador - PNQ (2003-2007). Ministério do Trabalho e Emprego, 2003.

MEC. Relatório de Gestão - Exercício 2013. Brasília/DF, março de 2014. Disponível em:

<http://portal.mec.gov.br/index.php?option=com_docman\&view=download \&alias $=15993$-relatorio-gestao-exercicio-2013-secadi-pdf\&Itemid=30192>. Acesso em: $30 / 06 / 2018$.

\section{MEC. Prestação de Contas Ordinárias Anual Relatório de Gestão do Exercício}

De 2014. Brasília/DF, abril de 2015. Disponível em $<$ http://portal.mec.gov.br/index.php?

option $=$ com_docman\&view $=$ download\&alias $=17528$-fies-relatorio-gestao-pcoaexercicio-2014-tcu\&Itemid=30192 > . Acesso em: 30/06/2018.

Lei $n^{\circ}$ 13.005, de 25 de junho de 2014. Aprova o Plano Nacional de Educação PNE e dá outras providências. Diário Oficial da União - Seção 1 - Edição Extra 26/6/2014, Página 1. Brasília, 2014.

Lei $n^{\circ} 11.892$, de 29 de dezembro de 2008. Institui a Rede Federal de educação profissional, Científica e Tecnológica, cria os Institutos Federais de Educação, Ciência e Tecnologia. Diário Oficial da União - Seção 1 - 30/12/2008, Página 1. Brasília, 2008. 
Lei no 12.513, de 26 de outubro de 2011. Institui o Programa Nacional de Acesso ao Ensino Técnico e Emprego (PRONATEC). Diário Oficial da União - Seção 1 27/10/2011, Página 1. Brasília, 2011.

MEC/MTE/MF/MP/MDS. Exposição de Motivos E.M.I. N 019, de 28 de abril de 2011. Brasília, 2011. Disponível em <http://planalto.gov.br/ccivil_03/projetos/expmotiv/emi/ 2011/19-mec\%20mte\% 20mf\%20mp\%20 mds.htm>. Acesso em:30/06/2018.

BRAVERMAN, H. Trabalho e capital monopolista: a degradação do trabalho no século XX. Rio de Janeiro: Editora Guanabara, 1987.

COSTA, J. M. A. A política de educação básica brasileira instituída pelo plano de desenvolvimento da educação: relações intergovernamentais no contexto da nova gestão pública. 2014. 218 f. Tese (doutorado em educação). Programa de Pesquisa e Pós-graduação em Educação. Faculdade de Educação da Universidade da Bahia. Bahia, $2014 . \quad$ Disponível em: <http://bdtd.ibict.br/vufind/Record/UFBA_f8ad5aea80f4e96c19ef1c884df1a9bf/Details >. Acesso em: 15/12/2016.

CURY, C. R. J. A qualidade da educação brasileira como um direito. Educação e Sociedade. Campinas, v. 35, no 129. p. 1053-1066, out-dez 2014. Disponível em: <http://www.scielo.br/ pdf/es/v35n129/0101-7330-es-35-129-01053.pdf >. Acesso em: 05/02/2017

DOURADO, L. F. Federalismo, SNE e os obstáculos ao direito á educação básica. In: DOURADO, L. F., AZEVEDO, J. M. L. (Orgs.). Relações Federativas e Sistema Nacional de Educação. Camaragibe. PE. CCS Gráfica e Editora, 2016.

DUARTE, C. S. Direito público subjetivo e políticas educacionais. Fundação SEADE, São Paulo, v. 18, n. 2, p. 113-118, jun. 2004. Disponível em: <http://www.scielo.br/pdf/spp/v18n2 /a12v18n2.pdf>. Acesso em: 29/01/2017.

MARX, K. Manuscritos econômico-filosóficos. São Paulo: Boitempo, 2010.

FRIGOTTO. G. A produtividade da escola improdutiva 30 anos depois: Regressão social e hegemonia às avessas. Trabalho Necessário. Niterói, n. 20, ano 13. 2015. Disponível em: <http://www.uff.br/trabalhonecessario/images/TN 20/10 frigotto.pdf> Acesso em: $19 / 05 / 2016$

GENTILLI, A. Falsificação do consenso: simulacro e imposição na reforma educacional do neoliberalismo. Rio de Janeiro: Editora Vozes, 1998.

HIRSCH, J. Teoria materialista do Estado: processos de transformação do sistema capitalista e de Estados. Rio de Janeiro: Revan, 2010.

HORTA, J. S. B. Direito à educação e obrigatoriedade escolar. Caderno de pesquisa, $\mathrm{n}^{0}$ 104, p. 5-34, jul. 1998. Disponível em: <http://www.fcc.org.br/pesquisa/publicacoes/cp/arquivos /158.pdf>. Acesso em: 10/08/2016

SAVIANI, D. Trabalho e educação: fundamentos ontológicos e históricos. Universidade Estadual de Campinas, Faculdade de Educação. Revista Brasileira de Educação, v. 12, n.34, p. 152 a 180. jan/abr 2007. 
STREMEL, S. A constituição do campo acadêmico da política educacional no Brasil. Ponta Grossa: tese de doutoramento PPGE-UEPG, 2016.

POULANTZAS, N. O Estado, o poder, o socialismo. Rio de Janeiro: Edições Graal, 1980.

SCAFF, E. A. S.; PINTO, I. R. R. O Supremo Tribunal Federal e a garantia do direito à educação. Autores Associados, Revista brasileira de Educação, v. 21, nº 65, abr-jun, 2016.

WERLE, F. O. C. Regime de colaboração: cooperação e colaboração federativa e intergovernamental. In: Dourado, L. F., Azevedo, J. M. L. (Orgs.). Relações federativas e sistema nacional de educação. Camaragibe. PE. CCS Gráfica e Editora, 2016. 